\title{
Recycling of biogas digestates in plant production: NPK fertilizer value and risk of leaching
}

\author{
Trine A. Sogn ${ }^{1}$ (D) Ivan Dragicevic ${ }^{1} \cdot$ Roar Linjordet $^{3} \cdot$ Tore Krogstad $^{1} \cdot$ Vincent G. H. Eijsink $^{2}$. \\ Susanne Eich-Greatorex ${ }^{1}$
}

Received: 3 August 2017 / Accepted: 16 December 2017 / Published online: 8 January 2018

(c) The Author(s) 2018. This article is an open access publication

\begin{abstract}
Purpose The main purposes of the study were to assess the NPK fertilizer value of biogas digestates in different soils and to evaluate the risk of unwanted nutrient leaching.

Methods The fertilizer value of digestates from anaerobic digesters was investigated in a greenhouse pot experiment with wheat in three different soils; silt, loam and sand. The digestates were based on different feedstock and had a low, dry matter content. The fertilizing effect of digestates was compared to mineral fertilizer and manure. To investigate the fate of excess nutrients in soil after the growing season, the pots were leached after harvest. A complementary soil column leaching experiment without plants was carried out in the laboratory.

Results The concentration of ammonium in digestates provided a good indicator of the nitrogen fertilizer value of the digestates. In the silt and loam, the ammonium $\mathrm{N}$ fraction in digestates had a fertilizer replacement value equal to that of mineral fertilizer N, whereas the replacement value was higher in the nutrient poor sandy soil. Digestates often have a ratio between nitrogen, phosphorus and potassium which is not favourable for plant growth. However, the suboptimal balance did not result in reduced plant growth or unwanted leaching from soil.

Conclusions The results show that digestates from biogas production based on fundamentally different feedstock are promising as NPK fertilizers. The $\mathrm{N}$ fertilization can simply be based on the digestate $\mathrm{NH}_{4}{ }^{+}$concentration and, at least for wheat production, considerable variation in the concentrations of $\mathrm{K}$ and $\mathrm{P}$ can be tolerated.
\end{abstract}

Keywords Digestates $\cdot$ Fertilizer $\cdot$ Nitrogen $\cdot$ Phosphorus $\cdot$ Potassium

\section{Introduction}

The core of the bioeconomy is the change from use of fossil raw materials to sustainable production, refinement and utilization of renewable biomass. For instance, production of biogas using organic waste as feedstock represents a plausible activity within the bioeconomy. Organic waste becomes a valuable resource, and compared to fossil fuel utilization, use of biogas yields a reduced carbon footprint

Trine A. Sogn

trine.sogn@nmbu.no

1 Faculty of Environmental Sciences and Natural Resource Management, Norwegian University of Life Sciences, Ås, Norway

2 Faculty of Chemistry, Biotechnology and Food Science, Norwegian University of Life Sciences, Ås, Norway

3 Norwegian Institute of Bioeconomy Research, Ås, Norway
(Rehl and Müller 2013; Uusitalo et al. 2014). Biogas production through anaerobic digestion leaves organic residues, digestates, which are rich in nutrients. If these digestates are utilized in plant production, nutrients already within the nutrient cycle will be recycled and the sustainability of the biogas production process improves (Arthurson 2009; Ladanai and Vinterbäck 2009; Vaneeckhaute et al. 2013). In addition, use of organic fertilizers contributes to maintaining and/or improving soil quality (Hati et al. 2006).

Utilization of digestates may replace or at least reduce the use of mineral fertilizer in agronomic plant production. The liquid phase of digestates is usually rich in plant-available nutrients such as ammonium $\left(\mathrm{NH}_{4}{ }^{+}\right)$, phosphate and potassium $(\mathrm{K})$. Additionally, more nitrogen $(\mathrm{N})$ will be plant available by microbial decomposition and mineralization of the digestates' solid phase. As anaerobic digestion produces methane $\left(\mathrm{CH}_{4}\right)$ gas from the organic feedstock, which is subsequently removed for use as biogas, the digestates have a 
lower carbon to nitrogen ratio $(\mathrm{C} / \mathrm{N}$ ratio) than the feedstock (Möller and Müller 2012). Although dependent on decomposition time, a $\mathrm{C} / \mathrm{N}$ ratio lower than about 25 usually entails that the organic matter has a surplus of $\mathrm{N}$ relative to the $\mathrm{N}$ demand of the soil microbial community, which then can be mineralized to $\mathrm{NH}_{4}{ }^{+}$, i.e. plant-available mineral N (Ferris et al. 1998).

Since farmers have to base their $\mathrm{N}$ fertilizer strategy on farm level $\mathrm{N}$ budgets with relatively high precision, the mineral $\mathrm{N}$ fertilizer equivalents or replacement values of different digestates are of importance. Studies with manure have shown low plant availability and then little effect from the organic $\mathrm{N}$ on plant growth in the first year of application due to slow mineralization (Möller and Müller 2012; Webb et al. 2013). On the other hand, the $\mathrm{NH}_{4}{ }^{+}$in the liquid phase is plant-available (Gutser et al. 2005) and may be directly comparable with mineral $\mathrm{N}$ fertilizer. Nevertheless, it is common practice for farmers to estimate the fertilization value of manure by considering a small part of organically bound $\mathrm{N}$ and a reduced effectiveness of the mineral $\mathrm{N}$ (Kirchmann 1985), the latter in order to allow for gaseous and/or leaching losses at application and during the growing season. A major challenge with all organic fertilizers is the predictability of the additional mineral $\mathrm{N}$ release by decomposition of the organic matter. Assessments of the fertilizer potential of digestates have been carried out (Alburquerque et al. 2012; Kuszel and Lorencowicz 2015; Cavalli et al. 2016; Riva et al. 2016), but due to the wide variety of feedstock used for biogas production, the efficiency and exact predictability of the fertilizer $\mathrm{N}$ value of digestates is difficult. Over time, organic $\mathrm{N}$ in the solid phase of digestates will be mineralized and $\mathrm{NH}_{4}{ }^{+}$will be released. In a production system with a continuous plant cover, the residual effect due to mineralization is positive as it ensures a gradual supply of $\mathrm{NH}_{4}{ }^{+}$to the plants. However, in cereal production, the timing of the mineralization is crucial. For example, release of mineral $\mathrm{N}$ late in the growing season, when plants have less requirement for $\mathrm{N}$, or in seasons without plant cover, will increase the risk of nitrate $\left(\mathrm{NO}_{3}{ }^{-}\right)$leaching. In agricultural areas with only one growing season per year and then often months without plant cover, release of mineral $\mathrm{N}$ from organic matter decomposition may increase the risk of $\mathrm{N}$ leaching.

Next to N, K and phosphorus (P) are quantitatively the most important plant nutrients and essential to secure proper growth and development. Phosphorus and $\mathrm{K}$ in the feedstock are generally retained during the anaerobic digestion process (Zirkler et al. 2014). In addition to dissolved inorganic phosphate in the liquid phase, the solid phase of the digestates contains both inorganic and organic P (Kataki et al. 2017). As a surplus of phosphate in soils may eventually lead to eutrophication of freshwater resources and estuaries, it is important to avoid overdosing of $\mathrm{P}$, by balancing the $\mathrm{P}$ and $\mathrm{N}$ input. In plants, $\mathrm{K}$ is not built into organic complexes but retained in cationic form. Consequently, the $\mathrm{K}$ in digestates derived from plant material is directly plant-available both in the solid and liquid phase. Some grass plant species are known to have a higher uptake of $\mathrm{K}$ than required in the metabolism at high K availability (Øgaard et al. 2001). An excessive $\mathrm{K}$ uptake may be problematic due to antagonisms with magnesium, resulting in nutrient imbalances with negative consequences for growth and quality (e.g. digestibility) (Masters and Thompson 2016). Thus, also the amount of K relative to $\mathrm{N}$ and $\mathrm{P}$ is important for optimized fertilization.

Organic material in soil is not only important as a source of plant nutrients, it is also important for soil porosity and structure, as well as the ability to store water and nutrients. Soils low in organic matter are often compact, have poor structure and low nutrient binding capacity, as well as a low ability to store water.

This study was aimed at evaluating the impact of widely different feedstocks for biogas production on the mineral $\mathrm{N}$ fertilizer replacement values of the resulting digestates, as well as the $\mathrm{P}$ and $\mathrm{K}$ supply to grain crops and potential losses through leaching. To assess these issues we have carried out a greenhouse experiment with wheat, using five different digestates derived from biogas reactors running on different combinations of manure, whey permeate, fish silage, food waste and sewage sludge, in three different soils. We have compared plant growth as well as nutrient leaching in treatments with digestates with data obtained from control treatments, including no fertilization, application of mineral fertilizer and fresh manure. A supplementary soil column leaching experiment without plants was carried out in the laboratory in order to study nutrient leaching from soils without plants.

\section{Materials and methods}

\section{The digestates}

The experiments in this study included the following treatments: 1. Control without fertilization (C), 2. Mineral fertilizer (MF), 3. Fresh manure (FM), 4. Digested manure (EDM), 5. Whey permeate co-digested with manure (EWM), 6 . Whey permeate and fish silage co-digested with manure (EWMF), 7. Commercial digestates from source separated organic household waste (CF) and 8. Commercial digestates from source separated organic waste mixed with sewage sludge (CFS). The first three were controls (no fertilizer, mineral fertilizer and manure, respectively); the next three were experimental digestates produced in the biogas laboratory of the Norwegian University of Life Sciences and the Norwegian Institute of Bioeconomy Research, located $35 \mathrm{~km}$ south-east of the Norwegian capital Oslo, whereas the final two were digestates from commercial biogas plants. 
The experimental digestates were produced on a laboratory scale in continuously stirred tank reactors (CSTR, Dolly, Belach Bioteknik, Stockholm, Sweden) operating at $37{ }^{\circ} \mathrm{C}$ with a working volume of $6 \mathrm{~L}$, and a hydraulic retention time of 20 days.

Treatment 4 used an experimental digestate from a reactor fed with manure only (EDM). The experimental digestates used in treatments 5 and 6 were produced in reactors fed with a mixture of whey permeate and manure in a volume $(\mathrm{mL})$ ratio of 70 to 230 (EWM) and 180 to 120 (EWMF), respectively. The latter digestate (EWMF) also included $6 \mathrm{~mL}$ fish silage in the feedstock mixture, in order to reduce the $\mathrm{C} / \mathrm{N}$ ratio. Organic loading rates for EDM, EWM and EWMF were $3.4,4.3$ and $5.4 \mathrm{~g}$ volatile solids (VS) $\mathrm{L}^{-1}$ day $^{-1}$, respectively. The digestates used in treatments 7 and 8 were commercial digestates collected from municipal biogas plants. The digestate in treatment $7(\mathrm{CF})$ was from a commercial biogas plant where biogas is produced on source separated organic household waste. The digestate in treatment 8 (CFS) was from a commercial biogas plant where biogas is produced based on source-separated organic household waste mixed with sewage sludge (50:50, based on fresh weight).

\section{The pot experiment}

A pot experiment was carried out in a greenhouse with wheat (Triticum aestivum L.var. Zebra) as a test crop. The pots had a soil volume of approximately $6.7 \mathrm{~L}$. Assuming a soil depth of $20 \mathrm{~cm}, 300,000$ pots correspond to one hectare (ha) of arable land. Three different soils: sand, silt and loam (Table 2), were used as growth media. The pots were irrigated regularly in order to keep the soil water content at $60 \%$ of the soils' water holding capacity (WHC) throughout the experiment. No water was leached from the pots during the experiment. The experiment consisted of the eight treatments as explained above. The mineral fertilizer treatment (MF) corresponded to a dose of approximately
$120 \mathrm{~kg} \mathrm{~N} \mathrm{ha}^{-1}, 20 \mathrm{~kg} \mathrm{P} \mathrm{ha}^{-1}$ and $180 \mathrm{~kg} \mathrm{~K} \mathrm{ha}^{-1}$. The NPK level was based on common fertilizer recommendation for wheat production in Norway, but adjusted in order to give optimal wheat growth in pots within a greenhouse. Because release of plant-available mineral $\mathrm{N}$ from the manure and the solid fraction of the digestates usually is low during the first growing season after application due to slow mineralization (Svensson et al. 2004), the amounts of manure and digestates were adjusted based on their inorganic $\mathrm{N}$ content, i.e. $\mathrm{NH}_{4}{ }^{+}$concentration (Tables 1 and 3) in wet samples only. Since the treatments (1-8) varied in percent DM, the soil moisture was adjusted by application of deionised water according to weight after the initial addition of fertilizers in order to achieve a soil moisture at $60 \%$ WHC. To reduce plant growth effects due to differences in soil pH (Table 2), 20 and $10 \mathrm{~g}$ calcium carbonate $\left(\mathrm{CaCO}_{3}\right)$ per pot were added to the loam and sand, respectively, bringing the $\mathrm{pH}$ up to approximately 6.2.

Plants were harvested after 14 weeks of growth by cutting the wheat straws one $\mathrm{cm}$ above the soil surface, and divided into cereal grain and straw after drying at $60{ }^{\circ} \mathrm{C}$ to constant weight.

\section{Leaching experiment after harvest}

In order to evaluate the risk of nutrient leaching after the growing season, a simple leaching study was conducted after the harvest. For that purpose, the pots were first irrigated to $100 \% \mathrm{WHC}$ and then leached with $1 \mathrm{~L}$ deionized water, added in doses of $250 \mathrm{~mL}$ each during the course of an hour. The leachate drained from the soil through a tube at the base of the pots.

\section{Soil leaching experiment without plants}

Another leaching experiment was carried out with bare soils in the laboratory. This study was intended to represent a worst-case scenario with extremely heavy rainfall just after

Table 1 Chemical characteristics of the manure and the digestates (treatments 3 to 8 ) used in the experiments

\begin{tabular}{|c|c|c|c|c|c|c|c|c|}
\hline Treatments & DM \% & $\mathrm{pH}$ & Tot $\mathrm{C} \mathrm{g} \mathrm{kg}^{-1}$ & Tot $\mathrm{N}^{\mathrm{a}} \mathrm{g} \mathrm{kg}^{-1}$ & $\begin{array}{l}\mathrm{NH}_{4}-\mathrm{N}+\mathrm{NO}_{3}-\mathrm{N}^{\mathrm{b}} \\
\mathrm{g} \mathrm{L}^{-1}\end{array}$ & $\begin{array}{l}\mathrm{NH}_{4}-\mathrm{N}+\mathrm{NO}_{3}-\mathrm{N}^{\mathrm{c}} \\
\mathrm{g} \mathrm{kg}^{-1}\end{array}$ & $\mathrm{Pg} \mathrm{kg}^{-1} \mathrm{DM}$ & $\mathrm{Kg} \mathrm{kg}^{-1} \mathrm{DM}$ \\
\hline 3. FM & 5.5 & 7.4 & 414 & 21 & $\mid 1.4$ & 25.4 & 6.4 & 62.3 \\
\hline 4. EDM & 4.7 & 7.7 & 351 & 27 & 0.9 & 20.0 & 11.5 & 82.0 \\
\hline 5. EWM & 4.6 & 7.6 & 382 & 25 & 1.4 & 29.3 & 8.4 & 76.0 \\
\hline 6. EWMF & 4.5 & 7.0 & 378 & 31 & 0.7 & 16.3 & 15.0 & 100 \\
\hline 7. $\mathrm{CF}$ & 2.9 & 7.6 & 397 & 57 & 1.1 & 39.5 & 9.1 & 46.3 \\
\hline 8. CFS & 1.7 & 6.9 & 318 & 42 & 0.9 & 53.3 & 16.0 & 8.6 \\
\hline
\end{tabular}

${ }^{\mathrm{a}} \mathrm{g}$ per $100 \mathrm{~g}$ DM, i.e. measured in samples dried at $55^{\circ} \mathrm{C}$

${ }^{\mathrm{b}}$ Measured in fresh samples

${ }^{\mathrm{c}}$ Calculated based on the measured concentration in fresh samples and DM\% 


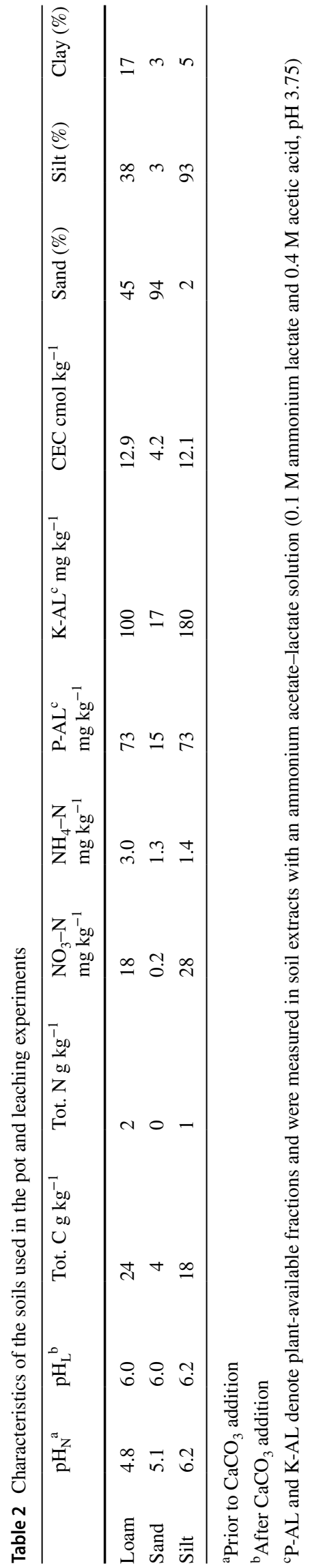

adding the different fertilizers. Plexiglass columns of $24 \mathrm{~mm}$ in diameter and $30 \mathrm{~cm}$ in length were filled with $15 \mathrm{~cm}$ of the same three soils as in the greenhouse pot experiment, i.e. sand, silt and loam (Table 2). In order to prevent soil loss during the leaching experiment, a plastic filter covered with PVC pellets ( $2 \mathrm{~mm}$ diameter) was placed at the bottom of the columns. The top of each column was also covered with PVC pellets in order to secure effective distribution of the added water. Each column was covered with tinfoil in order to prevent light exposure and thereby minimize algae growth within the columns. The treatments were the same as in the growth experiment (Table 3) and amounts of fertilizer added per volume of soil ( $\mathrm{mL}$ per $\mathrm{L}$ soil) corresponded to those in the growth experiment. Prior to leaching, the soil columns were saturated with deionized water. The columns were then irrigated with deionized water at a flow rate of $1.3 \mathrm{~mL} \mathrm{~h}^{-1}$ corresponding to $500 \mathrm{~mm}$ of precipitation during a 7 days period. The leachates were collected at the base of the column every day during the 7 days and filtered prior to analysis.

\section{Chemical analysis}

Chemical characteristics of the different digestates, as well as of the manure used in the experiments, are given in Table 1. Total $\mathrm{C}$ and $\mathrm{N}$ in manure and digestates were measured in dried and crushed samples by dry combustion (Nelson and Sommers 1982) at $1050^{\circ} \mathrm{C}$, using a Leco CHN1000 instrument (St. Joseph, Michigan, USA) according to the Dumas method (Bremner and Mulvaney 1982). $\mathrm{NH}_{4}{ }^{+}$in fresh digestates and manures was measured by flow injection analysis (FIA) after extraction with $2 \mathrm{M}$ potassium chloride $(\mathrm{KCl})$ as described in Bremner (1965). For the determination of the total concentrations of $\mathrm{P}$ and $\mathrm{K}$, the manure and digestates were digested in concentrated ultrapure nitric acid for 90 min by stepwise heating up to $250{ }^{\circ} \mathrm{C}$ using a Milestone Ultraclave and analysed using Inductively Coupled Plasma Mass Spectrometry (Agilent ICP-MS 8800 TripleQ).

The soil $\mathrm{pH}$ was measured in deionised water, with a soil to liquid ratio equal to $1: 2.5$. The total $\mathrm{C}$ and $\mathrm{N}$ in the soil was determined in dried and crushed samples by dry combustion (Nelson and Sommers 1982) at $1050{ }^{\circ} \mathrm{C}$, using a Leco CHN-1000 instrument (St. Joseph, Michigan, USA) as described above for manure and digestates. The soil content of $\mathrm{NH}_{4}{ }^{+}$and $\mathrm{NO}_{3}{ }^{-}$was measured by flow injection analysis (FIAstar 5000, based on ISO 13395-1996 and EN ISO 11732:1997) after extraction with $2 \mathrm{M} \mathrm{KCl}$. Plant-available $\mathrm{P}$ (P-AL) and $\mathrm{K}$ (K-AL) were estimated by extraction with an ammonium acetate-lactate solution $(0.1 \mathrm{M}$ ammonium lactate and 0.4-M acetic acid, pH 3.75) (Egnér et al. 1960), followed by inductively coupled plasma optical emission spectrometry (ICP-OES, Perkin Elmer Optima 5300 DV). 
Table 3 Treatments 1-8 expressed as element addition (mg) per pot

\begin{tabular}{|c|c|c|c|c|c|c|}
\hline \multicolumn{2}{|c|}{ Treatments } & \multirow{2}{*}{$\begin{array}{l}\text { Manure/digestate } \mathrm{mL} \\
\text { pot }^{-1 \mathrm{~b}}\end{array}$} & \multirow[t]{2}{*}{$\mathrm{N}^{\mathrm{a}}: \mathrm{P}: \mathrm{K}$ ratio } & \multirow{2}{*}{$\begin{array}{l}\mathrm{N}^{\mathrm{a}} \\
\mathrm{mg} \mathrm{p}\end{array}$} & \multirow{2}{*}{$\begin{array}{l}\mathrm{P} \\
-\end{array}$} & \multirow{2}{*}{$\begin{array}{c}\mathrm{K} \\
-\end{array}$} \\
\hline 1. & $\mathrm{C}$ & & & & & \\
\hline 2. & MF & & $4: 1: 6$ & 396 & 75 & 600 \\
\hline 3. & FM & 286 & $4: 1: 10$ & 400 & 101 & 980 \\
\hline 4. & EDM & 422 & $4: 2: 16$ & 397 & 228 & 1626 \\
\hline 5. & EWM & 294 & $4: 1: 10$ & 399 & 114 & 1028 \\
\hline 6. & EWMF & 540 & $4: 4: 24$ & 399 & 365 & 2430 \\
\hline 7. & $\mathrm{CF}$ & 349 & $4: 1: 5$ & 399 & 91 & 461 \\
\hline 8. & CFS & 441 & 4:1:1 & 399 & 119 & 64 \\
\hline
\end{tabular}

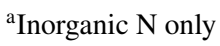

${ }^{\mathrm{b}}$ The doses multiplied with 0.3 correspond to $\mathrm{kg}$ per hectare. The doses divided by 100 correspond to $\mathrm{mg}$ per soil column in the soil column experiment
The particle size distribution (i.e. percent of sand, silt and clay in the soil, Table 2) was determined by the pipette method (Elonen 1971).

The leachates from the pots after harvest and from the soil column experiment were analysed for ammonium $\left(\mathrm{NH}_{4}-\mathrm{N}\right)$ and nitrate $\left(\mathrm{NO}_{3}-\mathrm{N}\right)$ by flow injection analysis (FIAstar 5000, based on ISO 13395-1996 and EN ISO 11732:1997) and for other nutrients by ICP-OES (Perkin Elmer Optima $5300 \mathrm{DV})$.

\section{Calculations and statistical analysis}

The mineral $\mathrm{N}$ fertilizer replacement value is the ratio between the grain yield obtained in the digestates or manure treatments (treatments 3-8) and the grain yield obtained in the mineral $\mathrm{N}$ fertilizer treatment.

The total biomass and grain yield figures in $\mathrm{tha}^{-1}$ are calculated by multiplying the amounts measured in $\mathrm{g} \mathrm{DM} \mathrm{pot}{ }^{-1}$ with a factor 0.3 . The factor is generated assuming a soil depth of $20 \mathrm{~cm}$ and thus 300,000 pots of $6.7 \mathrm{~L}$ correspond to one hectare (ha) arable land. The 300,000 ha are divided by $10^{6}$ to convert from gram to tons of biomass or grain yield.

Each treatment, both in the column and pot experiments, was replicated three times for each soil. Treatment and soil effects were tested statistically by analysis of variance and multiple testing using the GLM and Student-Neuman-Keul's test (SNK) available in the SAS computer work package (SAS v.9.4). Differences were considered significant at $p<0.05$.

\section{Results and discussion}

\section{Biomass and yield}

Digestates generally had the same fertilizing effect on total biomass and grain yields as manure, with manure being

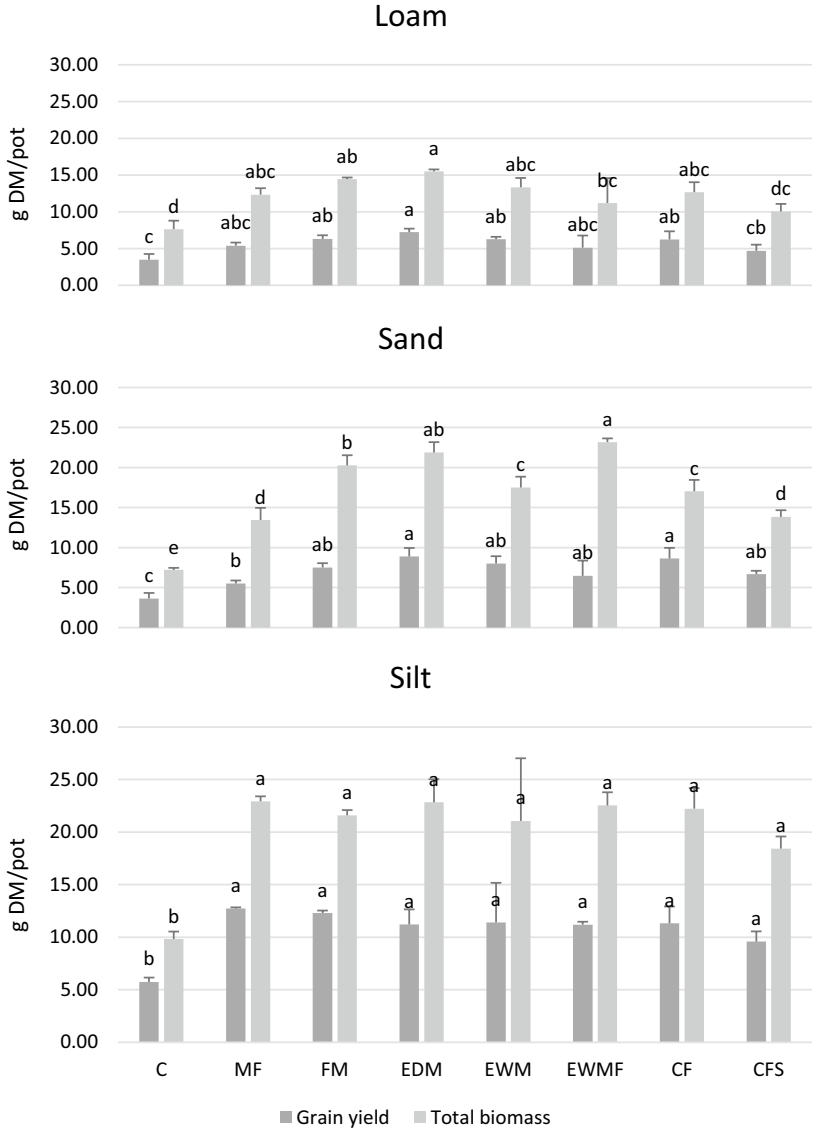

Fig. 1 Total biomass (g DM pot $\left.{ }^{-1}\right)$ and grain yield $\left(\mathrm{g} \mathrm{DM} \mathrm{pot}^{-1}\right)$ in loam, sand and silt. The standard deviation within each treatment $(n=3)$ is indicated by the line extending the column. Within each soil, significant differences are indicated by letters

similar to or better than mineral fertilizer (Fig. 1. Multiplying the figures $\left(\mathrm{g} \mathrm{DM}\right.$ pot $\left.^{-1}\right)$ with a factor 0.3 gives total biomass and grain yield in $\mathrm{tha}^{-1}$ ). Total biomass and grain yields were generally lower in sand and loam compared to silt, with an average grain yield across the treatments 
corresponding to $1.7 \mathrm{t} \mathrm{ha}^{-1}$ in the loam, $2.1 \mathrm{tha}^{-1}$ in the sand and $3.2 \mathrm{tha}^{-1}$ in the silt. The organic fertilizers showed a significantly positive biomass effect (not significant for the CFS treatment) relative to the mineral fertilizer in the sand only.

The variation in grain yield coincided generally with the variation in total biomass production. Figure 1 shows that in the silt and loam, the nitrogen fertilizer replacement value (NFRV) (Webb et al. 2013) for manure and digestates is approximately 1 , when based on the $\mathrm{NH}_{4}{ }^{+}$concentration measured in the fresh samples of the digestates (Table 1). In the sand, the NFRVs of manure and digestates seem to be higher than 1 (significant only for the EDM and CF treatments). The poor growth of wheat plants receiving mineral fertilizer may be connected to the high mobility of mineral $\mathrm{N}$ in sand. Due to their content of organic material, manure and digestates may contribute to keeping plant-available $\mathrm{N}$ in the top layer of the soil at the beginning of the growing season, thus ensuring a sufficient supply while the root systems is not yet well developed. Mineral fertilizer-based N will easily be washed down in the sandy soil due to lack of binding sites. The sand is a soil poor in nutrients and with a low content of organic matter (Table 2) and as such a growth medium in which positive effects of digestates are expected. In addition to the effect of the organic matter addition on improving nutrient availability, other plant growth conditions, such as water-holding capacity are likely to improve.

Since the manure and digestates varied in nutrient concentrations (Table 1), and the amount of manure and digestates applied to the pots in the different treatments was adjusted to give the same mineral $\mathrm{N}$ input, the input of $\mathrm{P}$ and $\mathrm{K}$ varied in the different treatments (Table 3 ). No additional fertilizer was applied in order to compensate for these differences. In the mineral fertilizer treatment, the ratio between $\mathrm{N}, \mathrm{P}$ and $\mathrm{K}$ was 4:1:6. The commercial digestate based on food waste (CF) had almost the same balance between N, P and K as the mineral fertilizer, while the experimental digestate based on whey permeate, manure and fish silage (EWMF) represented the highest input of both $\mathrm{P}$ and $\mathrm{K}$ relative to the mineral fertilizer (4:4:24; Table 3). Although the mineral fertilizer treatment represents an adequate balance between the macronutrients $\mathrm{N}, \mathrm{P}$ and $\mathrm{K}$ for wheat, it is still possible that growth in sand, which is poor in nutrients (Table 1), was stimulated by the extra supply of $\mathrm{P}$ and $\mathrm{K}$ in the manure and some of the digestates. However, also the digestates not particularly rich in $\mathrm{P}$ and $\mathrm{K}$ resulted in good yields on the sandy soil (Fig. 1) and the differences among the manure and digestates were not significant. There was no clear overall trend. The $\mathrm{N}$ to $P$ ratio in the organic amendments was never lower than in the mineral fertilizer treatment, i.e. 4 to 1 , but the supply of $\mathrm{K}$ was lower in treatments with commercial digestates (CF and CFS). No symptoms related to K deficiency were seen on the wheat plants in any of the soils and treatments. Thus, all in all it seems that all digestate treatments (Table 3) provided $\mathrm{P}$ and $\mathrm{K}$ in amounts and ratios which can be regarded adequate, i.e. within a range suitable for wheat production. This is in line with Tambone et al. (2010) who, based simply on chemical, spectroscopic and biological characteristics of several digestates appraised digestates to have good fertilizing properties just due to a high content of $\mathrm{N}, \mathrm{P}$ and $\mathrm{K}$ in easily available form. However, no plant growth experiments were conducted in that study.

In the silt and loam, application of manure and digestates resulted in the same biomass production and grain yield as application of mineral fertilizer. Independent of treatment, the lowest biomass and grain yields were observed in the loam (Fig. 1). This was most likely due to limited air supply (Currie 1962) since the sieved loam provides a dense growth medium upon irrigation. Notably, in this study the dense loam was not improved by application of organic matter.

\section{Leaching}

\section{Nitrogen}

Nitrogen applied to soil as $\mathrm{NH}_{4}{ }^{+}$will rapidly nitrify to $\mathrm{NO}_{3}{ }^{-}$if not taken up by plants. Both $\mathrm{NH}_{4}{ }^{+}$and $\mathrm{NO}_{3}{ }^{-}$are plant-available, but cereals in general prefer $\mathrm{NO}_{3}{ }^{-}$(Cramer and Lewis 1993). A surplus of $\mathrm{NO}_{3}{ }^{-}$in soil relative to the plant requirement will be leached after harvest or denitrified. Generally, the $\mathrm{NO}_{3}{ }^{-}$leaching from the pots after harvest

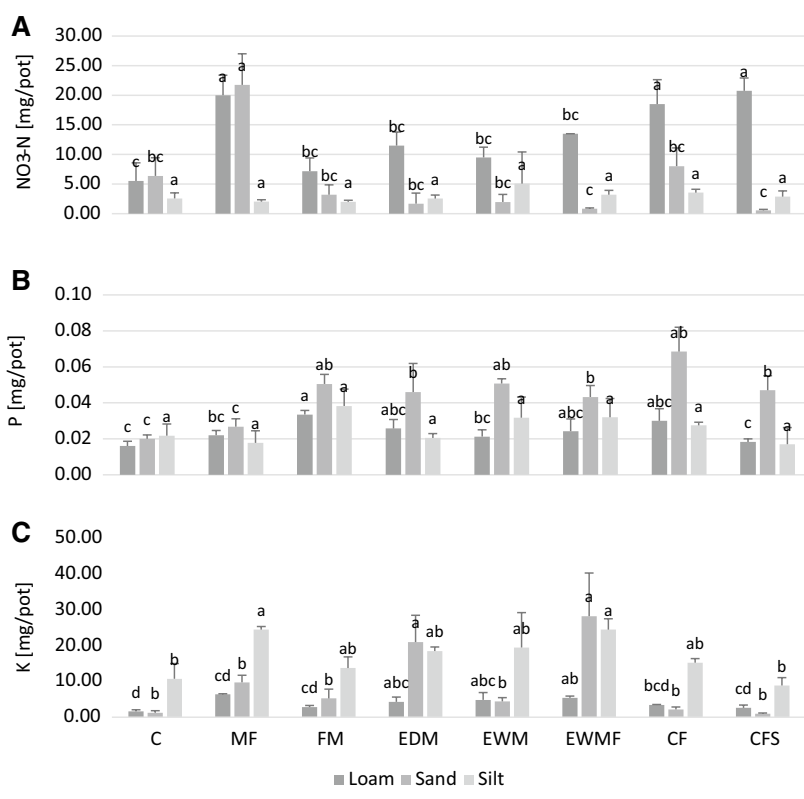

Fig. 2 Leaching of $\mathrm{NO}_{3}-\mathrm{N}(\mathbf{a})$, total $\mathrm{P}(\mathbf{b})$ and total $\mathrm{K}(\mathbf{c})\left(\mathrm{mg} \operatorname{pot}^{-1}\right)$ measured after harvest in the pot experiment. The standard deviation within each treatment $(n=3)$ is indicated by the line extending the column. Within each soil, significant differences are indicated by letters 
(Fig. 2a) was negatively related to the biomass growth, i.e. high biomass growth resulted in low $\mathrm{NO}_{3}{ }^{-}$leaching. Thus, across the fertilizer treatments, $\mathrm{NO}_{3}{ }^{-}$leaching was generally highest from the loam. Both in the sand and loam, high $\mathrm{NO}_{3}{ }^{-}$leaching was seen in the mineral fertilizer treatment (Fig. 2a). In these soils, the $\mathrm{N}$ given as $\mathrm{NO}_{3}{ }^{-}$(calcium nitrate) was not utilized by the plants. In the sand, the $\mathrm{NO}_{3}{ }^{-}$seemed to be leached towards the bottom of the pot before an effective root system had been developed. In the loam, root development might have been restricted by compactness, and thus, roots may physically not have been able to reach all the fertilizer $\mathrm{NO}_{3}{ }^{-}$. The compactness of the loam may restrict oxygen availability as well as root development, causing reduced uptake of mineral $\mathrm{N}$ during the period of vegetative growth when the plant $\mathrm{N}$ demand is at the highest. In the loam, $\mathrm{NO}_{3}{ }^{-}$leaching was reduced when manure and experimental digestates were applied (Fig. 2a), but the commercial digestate treatments (CF and CFS) showed the same high $\mathrm{NO}_{3}{ }^{-}$leaching as the MF treatment. Thus, the application of organic matter did not improve the $\mathrm{N}$ utilization in the compact loam in general. In the sand, rapid water flow towards the bottom of the pot may have limited the plants' ability to scavenge the nutrients. The $\mathrm{NO}_{3}{ }^{-}$leaching from pots treated with the manure or digestates was significantly lower compared to the MF treatment (Fig. 2a). This latter observation is in accordance with data from Svoboda et al. (2013) who, in field experiments with maize production in a sandy loam and a sand, found that $\mathrm{NO}_{3}{ }^{-}$leaching was lower upon treatment with digestates or manure, compared to treatment with mineral fertilizer. Interestingly in our experiments, $\mathrm{NO}_{3}{ }^{-}$leaching from sand receiving manure or digestates was mostly lower (significant for the EWMF and commercial digestates) than from sand not receiving any fertilizer. A similar inhibitory effect of organic fertilizer on $\mathrm{NO}_{3}{ }^{-}$leaching was found by Kramer et al. (2006) based on studies in an organic farming system. They suggested that the reduced $\mathrm{NO}_{3}{ }^{-}$leaching could be due to a positive effect of organic matter on the activity of the denitrifying microbial communities.

In the soil column leaching experiment, the amount of elements not retrieved in the leachate must be considered adsorbed in the soil or, in the case of $\mathrm{N}$, possibly also lost as gaseous $\mathrm{N}$ species. Generally only $50 \%$ or less of the mineral $\mathrm{N}$ added was leached (Table 4) despite the very high irrigation rate equivalent to $500 \mathrm{~mm}$ of precipitation during 7 days. When applied on agricultural land, manure is usually mechanically incorporated into the top soil to avoid ammonia $\left(\mathrm{NH}_{3}\right)$ losses. In the column experiment,
Table 4 Total amounts (mg) of N, P and K applied (in) and leached (out) within 7 days in the soil column experiment

\begin{tabular}{|c|c|c|c|c|c|c|c|c|}
\hline \multirow[t]{2}{*}{ Soil } & \multirow[t]{2}{*}{ Treatments } & \multicolumn{3}{|c|}{$\mathrm{N} \mathrm{mg} \mathrm{column}{ }^{-1}$} & \multicolumn{2}{|c|}{$\mathrm{P}_{\mathrm{mg}}$ column ${ }^{-1}$} & \multicolumn{2}{|c|}{$\mathrm{K} \mathrm{mg} \mathrm{column}^{-1}$} \\
\hline & & $\mathrm{N}$ in & $\mathrm{NO}_{3}-\mathrm{N}$ out & NH4-N out & $\mathrm{P}$ in & P out & $\mathrm{K}$ in & K out \\
\hline \multirow[t]{8}{*}{ Loam } & 1. $\mathrm{C}$ & - & 1.1 & 0.0 & - & 0.0 & - & 1.0 \\
\hline & 2. MF & 3.6 & 1.5 & 0.1 & 0.8 & 0.0 & 6 & 1.4 \\
\hline & 3. FM & 4.1 & 1.2 & 0.0 & 1 & 0.0 & 9.9 & 1.3 \\
\hline & 4. EDM & 4 & 1.3 & 0.0 & 2.3 & 0.0 & 16.2 & 1.1 \\
\hline & 5. EWM & 4 & 1.0 & 0.0 & 1.1 & 0.0 & 10.1 & 1.1 \\
\hline & 6. EWMF & 4 & 2.1 & 0.0 & 3.7 & 0.0 & 24.3 & 1.1 \\
\hline & 7. $\mathrm{CF}$ & 4 & 1.0 & 0.0 & 0.9 & 0.0 & 4.6 & 1.1 \\
\hline & 8. CFS & 4 & 0.9 & 0.0 & 1.2 & 0.0 & 0.6 & 0.9 \\
\hline \multirow[t]{8}{*}{ Sand } & 1. $\mathrm{C}$ & - & 0.0 & 0.0 & - & 0.0 & - & 0.4 \\
\hline & 2. MF & 3.6 & 0.7 & 0.0 & 0.8 & 0.0 & 6 & 4.7 \\
\hline & 3. FM & 4.1 & 0.0 & 0.7 & 1 & 0.1 & 9.9 & 5.9 \\
\hline & 4. EDM & 4 & 0.0 & 0.7 & 2.3 & 0.1 & 16.2 & 7.5 \\
\hline & 5. EWM & 4 & 0.0 & 0.6 & 1.1 & 0.1 & 10.1 & 5.6 \\
\hline & 6. EWMF & 4 & 0.0 & 0.8 & 3.7 & 0.2 & 24.3 & 15.4 \\
\hline & 7. $\mathrm{CF}$ & 4 & 0.0 & 0.4 & 0.9 & 0.1 & 4.6 & 1.4 \\
\hline & 8. CFS & 4 & 0.0 & 0.3 & 1.2 & 0.0 & 0.6 & 0.8 \\
\hline \multirow[t]{8}{*}{ Silt } & 1. $\mathrm{C}$ & - & 1.1 & 0.0 & - & 0.0 & - & 3.1 \\
\hline & 2. MF & 3.6 & 1.3 & 0.0 & 0.8 & 0.1 & 6 & 5.7 \\
\hline & 3. FM & 4.1 & 0.5 & 0.1 & 1 & 0.1 & 9.9 & 7.4 \\
\hline & 4. EDM & 4 & 1.2 & 0.6 & 2.3 & 0.2 & 16.2 & 10.0 \\
\hline & 5. EWM & 4 & 0.9 & 0.3 & 1.1 & 0.1 & 10.1 & 5.6 \\
\hline & 6. EWMF & 4 & 0.9 & 0.3 & 3.7 & 0.1 & 24.3 & 7.2 \\
\hline & 7. $\mathrm{CF}$ & 4 & 0.7 & 0.1 & 0.9 & 0.1 & 4.6 & 5.0 \\
\hline & 8. CFS & 4 & 1.0 & 0.5 & 1.2 & 0.0 & 0.6 & 4.1 \\
\hline
\end{tabular}


however, manure and digestates were applied on the top of the soil and washed into the soil with the waterfront. The air temperature in the laboratory was $20^{\circ} \mathrm{C}$. Although the soil surfaces were kept moist and also covered with pellets, the soil pH was 6 and slightly above (Table 2) after the liming and some $\mathrm{N}$ may have been volatilized as $\mathrm{NH}_{3}$. In the loam, $\mathrm{N}$ was mainly leached as $\mathrm{NO}_{3}{ }^{-}$, in the sand mainly as $\mathrm{NH}_{4}{ }^{+}$, while in the silt, both forms occurred in the leachate with the major part being $\mathrm{NO}_{3}^{-}$(Table 4). Although the loam is relatively compact and likely not rich in oxygen, the leaching data show that $\mathrm{NH}_{4}{ }^{+}$must have been nitrified to $\mathrm{NO}_{3}{ }^{-}$before leaching, an observation that probably reflects a combination of high microbial activity and high retention. $\mathrm{N}$ leaching from the sand treated with organic fertilizers occurred mainly as $\mathrm{NH}_{4}{ }^{+}$(Table 4), which is likely due to short retention times of non-adsorbed nitrogen in this porous soil. Still, N leaching in sand was generally less than $20 \%$ of the mineral $\mathrm{N}$ added. The cation exchange capacity of the sand is low, but might have been slightly improved by the organic matter addition. Thus, adsorption of $\mathrm{NH}_{4}{ }^{+}$to negative surface charges may occur in the organic fertilizer treatments. The fact that $\mathrm{NO}_{3}{ }^{-}$leaching was found in the mineral fertilizer treatment, but not in sand receiving digestates or manure suggests also a positive effect of organic matter on the activity of denitrifying microbial communities (Kramer et al. 2006). In the silt, the soil with the highest natural content of $\mathrm{NO}_{3}{ }^{-}$(Table 2), $\mathrm{N}$ leaching was generally higher than in the sand, but at the same level as in the loam. In the silt, the main part of the $\mathrm{N}$ leached was as $\mathrm{NO}_{3}{ }^{-}$, but a noticeable amount also as $\mathrm{NH}_{4}{ }^{+}$. Thus, in this simple and well-controlled soil system, $\mathrm{N}$ species and amounts leached following addition of organic fertilizer depended on the soil type.

\section{Phosphorus}

The doses of total $\mathrm{P}$ in the digestates and manure treatments were equal to or higher than the amount of phosphate applied in the mineral fertilizer treatment (Table 3). The leaching of $\mathrm{P}$ in the pot experiment was generally very low (Fig. 2b). For all the three soils, $\mathrm{P}$ leaching from the mineral fertilizer treatment was as low as in the pots with no fertilization. Though very low, $\mathrm{P}$ leaching for the organic fertilizer treatments in the sand was significantly higher compared to the no fertilizer and mineral fertilizer treatments. It is interesting to note that the EWMF digestate had more than 4 times higher $\mathrm{P}$ content than the mineral fertilizer and that this was not reflected in the amounts of leached P in any of the soils. This result is in contrast to findings by $\mathrm{Lu}$ and O'Connor (2001) who found considerable leaching of $\mathrm{P}$ from organic wastes when applied to course texture soils with low P-adsorption capacity. However, the low leaching of $\mathrm{P}$ from digestates found in our experiment corresponds somewhat better to the findings by Haraldsen et al. (2011) who investigated the fate of $\mathrm{P}$ from different organic waste products in a similar greenhouse pot experiment with barley growing in sand. They found low P leaching in general, but a somewhat higher $\mathrm{P}$ leaching from the digestates compared to other organic waste products. In a review by Lu et al. (2012) it is described that since most of the P in biosolids is in recalcitrant form, biosolids $\mathrm{P}$ may generally be less subjected to runoff loss compared to other amendments when applied to agricultural lands.

Results from the column experiment also showed very low levels of leached $P$ for all soils and treatments (Table 4). As the soil $\mathrm{pH}$ after liming was approximately 6 in all the three soils $\left(\mathrm{pH}_{\mathrm{L}}\right.$, Table 2$)$, neither sorption to Al- and Feoxides or precipitation with carbonates were processes expected to reduce the $\mathrm{P}$ leaching. At a soil $\mathrm{pH}$ of about 6 , the $\mathrm{P}$ added in all treatments seems to be effectively chemisorbed by ligand exchange on the soil minerals even in the short time-span considered in this study. Independent of the natural plant-available $\mathrm{P}$ status of the soils (P-AL, Table 2), which was low in the sand and higher in the loam and silt, the added $\mathrm{P}$ was effectively retained within the soils. In a column leaching study including soils with different texture, P-status and $\mathrm{pH}$ ranging from 5.8 to 7.9, GarcíaAlbacete et al. (2014) found the potential P losses connected to digestate application not to be significantly dependent on soil type, but more related to digestate characteristics. The increase of the soils' $\mathrm{P}$ reserves may be positive for soils naturally low in P. In a long-term field study by Bedada et al. (2016), a build-up of the soil P status by addition of compost compared to mineral fertilizer was emphasised. However, in areas prone to erosion, $\mathrm{P}$ supplies exceeding plant requirements will increase the risk of eutrophication of water bodies through transport of particle-bound P (Sharpley et al. 2001).

\section{Potassium}

Among the three soils, the silt had the highest natural $\mathrm{K}$ content (Table 2) and, when no fertilizer was added, higher amounts of $\mathrm{K}$ leached from the silt after harvest compared to loam and sand (Fig. 2c). Among the fertilizer treatments, the commercial digestates (CF and CFS) represented the lowest $\mathrm{K}$ input (Table 3), and $\mathrm{K}$ leaching from the pots receiving these digestates did not differ from the control without any fertilizer addition. As plant growth did not appear to be K-limited in the CF and CFS treatments (Fig. 1) and the leaching of $\mathrm{K}$ was equal to the control with no fertilizer addition (Fig. 2c), the low K concentration in the CF and CFS treatments apparently still met the wheat plant requirements even in the K-poor sand.

The treatments with experimental digestates EWMF and EDM represented the highest $\mathrm{K}$ input (Table 3), i.e. 2.6 and 
4 times, respectively, higher than for MF. The amount of K leached from loam and silt treated with EWMF and EDM was similar to the mineral fertilizer treatment, suggesting higher plant uptake and/or accumulation of $\mathrm{K}$ in the soil. For the sand, leached amounts of $\mathrm{K}$ were higher from the treatments with K-rich digestates and neither plant uptake nor accumulation in the soil seems to have played a major role. The addition of organic matter in the organic fertilizers has thus not improved $\mathrm{K}$ binding capacity in the sand. In the sand, which is naturally low in $\mathrm{K}$ (Table 2) and could thus have profited from an accumulation of $\mathrm{K}$, most of the extra $\mathrm{K}$ was leached.

In accordance with the data from the pot experiments, the soil column leaching experiments showed generally a strong $\mathrm{K}$ adsorption in the loam (Table 4). For the other two soils, varying degrees of leaching were observed (Table 4). Also in the soil column experiment, the naturally higher $\mathrm{K}$ content in the silt compared to the sand was reflected in the amount of $\mathrm{K}$ leached. In the sand $45-100 \%$ of the $\mathrm{K}$ added in the different fertilizer treatments was leached, and leaching was highest for the treatments with the highest $\mathrm{K}$ input, i.e. the EWMF and the EDM treatments. In the silt, $\mathrm{K}$ leaching was high for EDM, but for the other treatments generally lower compared to sand.

Fertilizer $\mathrm{K}$ input in excess of plant requirements often has been found to persist in soil for years after application, improving the soil K status (Yu et al. 2009; Zhang et al. 2011). Considering both the results from the soil column experiment and the after harvest leaching study, the effect of a $\mathrm{K}$ input in excess of plant requirements apparently varies dependent of soil type. In the silt, which in general had the highest biomass production, the high amount of $\mathrm{K}$ added was to a large extent taken up by the plants. In the loam with lower biomass production, the extra $\mathrm{K}$ was primarily adsorbed by the clay minerals, while excess $\mathrm{K}$ in the sand was predominantly leached from the system.

\section{Conclusion}

The present study provides an overview of how a wide variety of digestates affects plant production and leaching of nutrients. The results show that the concentration of $\mathrm{NH}_{4}{ }^{+}$ in digestates $(\mathrm{DM}<6 \%)$ provides a good indicator of the $\mathrm{N}$ fertilizer value of the digestates. Additionally, in the sand, digestate application reduced $\mathrm{NO}_{3}{ }^{-}$leaching. In longer-term applications of digestates in the field, additional $\mathrm{N}$ supply from mineralization of the organic material may benefit biomass production also in following growing seasons.

Particularly in the nutrient poor sand, the organic fertilizers had a positive effect on cereal yields. The positive effect may be related to an improved ability to keep plant nutrients within the root zone at an early stage of plant development.
Although most digestates had ratios between the plant macronutrients $\mathrm{N}, \mathrm{P}$ and $\mathrm{K}$ that were not optimal for wheat growth, the variation in $\mathrm{P}$ and $\mathrm{K}$ content seemed to be within a range suitable for wheat production. The risk of $\mathrm{P}$ leaching was low, even in the sandy soil or at a $\mathrm{P}$ input that was up to 4 times higher compared to adequate mineral fertilizer additions. The variation in $\mathrm{K}$ input did not influence yield. In the sand, $\mathrm{K}$ from digestates in excess of plant requirements was leached from the soil, in the loam assimilated in the soil leading to a soil K-reserve build-up, while in the silt, the higher $\mathrm{K}$ availability was met by a higher biomass production and/or soil accumulation.

Overall, the data show that digestates from biogas production based on fundamentally different feedstocks are promising as fertilizers. The $\mathrm{N}$ fertilization can be based only on the $\mathrm{NH}_{4}{ }^{+}$concentration of digestates and, at least for wheat production, considerable variation in the concentrations of $\mathrm{K}$ and $\mathrm{P}$ can be tolerated.

Acknowledgements We would like to thank Kurt R. Johansen for his help with the pot experiments, and Dr. Valentina Zivanovic, for her work with the soil and soil water analyses. This work was funded by the Norwegian Research Council (Project no. 203402/I10).

Open Access This article is distributed under the terms of the Creative Commons Attribution 4.0 International License (http://creativecomm ons.org/licenses/by/4.0/), which permits unrestricted use, distribution, and reproduction in any medium, provided you give appropriate credit to the original author(s) and the source, provide a link to the Creative Commons license, and indicate if changes were made.

\section{References}

Alburquerque JA, de la Fuente C, Ferrer-Costa A, Carrasco L, Cegarra J, Abad M, Bernal MP (2012) Assessment of the fertiliser potential of digestates from farm and agroindustrial residues. Biomass Bioenerg 40:181-189. https://doi.org/10.1016/j.biombioe.2012 .02 .018

Arthurson V (2009) Closing the global energy and nutrient cycles through application of biogas residue to agricultural landpotential benefits and drawbacks. Energies 2:226-242. https:// doi.org/10.3390/en20200226

Bedada W, Lemenih M, Karltun E (2016) Soil nutrient build-up, input interaction effects and plot level $\mathrm{N}$ and $\mathrm{P}$ balances under longterm addition of compost and NP fertilizer. Agric Ecosyst Environ 218:220-231. https://doi.org/10.1016/j.agee.2015.11.024

Bremner JM (1965) Inorganic forms of nitrogen. In: Black CA et al (eds) Methods of soil analysis, part 2. Agronomy, 1st edn. vol 9. American Society of Agronomy, Soil Science Society of America. pp 1179-1237

Bremner JM, Mulvaney CS (1982) Nitrogen-total. In: Page AL, Miller RH, Keeney DR (eds) Methods of soil analysis part 2. Chemical and microbial properties. vol 9.2. American Society of Agronomy, Soil Science Society of America. pp 595-624

Cavalli D, Cabassi G, Borrelli L, Geromel G, Bechini L, Degano L, Gallina PM (2016) Nitrogen fertilizer replacement value of undigested liquid cattle manure and digestates. Eur J Agron 73:34-41. https://doi.org/10.1016/j.eja.2015.10.007 
Cramer MD, Lewis OAM (1993) The influence of nitrate and ammonium nutrition on the growth of wheat (Triticum aestivum) and maize (Zea mays) plants. Ann Bot 72:359-365. https://doi. org/10.1006/anbo.1993.1119

Currie JA (1962) The importance of aeration in providing the right conditions for plant growth. J Sci Food Agric 13:380-385. http s://doi.org/10.1002/jsfa.2740130706

Egnér H, Riehm H, Domingo WR (1960) Untersuchungen über die chemische Boden- Analyse als Grundlage des Nährstoffzustandes der Böden. II. Chemische Extraktionsmethoden zur Phosphorund Kaliumbestimmung. Kungliga Lantbrukshögskolans Annaler 26:199-215

Elonen P (1971) Particle-size analysis of soil. Acta Agral Fenn 122:122p

Ferris H, Venette R, van der Meulen H, Lau SS (1998) Nitrogen mineralization by bacterial-feeding nematodes: verification and measurement. Plant Soil 203:159. https://doi.org/10.1023/A:10043183 18307

García-Albacete M, Tarquis AM, Cartagena MC (2014) Risk of leaching in soils amended by compost and digestate from municipal solid waste. Sci World J 2014:1-9. https://doi.org/10.1155/2014 1565174

Gutser R, Ebertseder T, Weber A, Schraml M, Schmidhalter U (2005) Short-term and residual availability of nitrogen after long-term application of organic fertilizers on arable land. J Plant Nutr Soil Sci 168:439-446. https://doi.org/10.1002/jpln.200520510

Haraldsen TK, Andersen U, Krogstad T, Sørheim R (2011) Liquid digestate from anaerobic treatment of source-separated household waste as fertilizer to barley. Waste Manag Res 29:1271-1276. http s://doi.org/10.1177/0734242X11411975

Hati KM, Mandal KG, Misra AK, Ghosh PK, Bandyopadhyay KK (2006) Effect of inorganic fertilizer and farmyard manure on soil physical properties, root distribution, and water-use efficiency of soybean in Vertisols of central India. Bioresour Technol 97:21822188. https://doi.org/10.1016/j.biortech.2005.09.033

Kataki S, Hazarika S, Baruah DC (2017) Assessment of by-products of bioenergy systems (anaerobic digestion and gasification) as potential crop nutrient. Waste Manag 59:102-117. https://doi. org/10.1016/j.wasman.2016.10.018

Kirchmann H (1985) Losses, plant uptake and utilization of manure nitrogen during a production cycle. Acta Agr Scand Suppl 24:1-77

Kramer S, Reganold JP, Glover JD, Bohannan BJM, Mooney HA (2006) Reduced nitrate leaching and enhanced denitrifier activity and efficiency in organically fertilized soils. PNAS 103:45224527. https://doi.org/10.1016/B978-0-12-407247-3.00007-X

Kuszel M, Lorencowicz E (2015) Agricultural use of biogas digestate as a replacement fertilizers. Agric Agric Sci Procedia 7:119-124. https://doi.org/10.1016/j.aaspro.2015.12.004

Ladanai S, Vinterbäck J (2009) Global Potential of Sustainable Biomass for Energy. Report 013. SLU, Swedish University of Agricultural Sciences. Available at http://pub.epsilon.slu.se/4523/1/ ladanai_et_al_100211.pdf

Lu P, O'Connor GA (2001) Biosolids effects on phosphorus retention and release in some sandy Florida soils. J Environ Qual 30:10591063. https://doi.org/10.2134/jeq2001.3031059x

Lu Q, He ZL, Stoffella PJ (2012) Land application of biosolids in the USA: a review. Appl Environ Soil Sci 2012:1-11. https://doi. org/10.1155/2012/201462

Masters DG, Thompson AN (2016) Grazing crops: implications for reproducing sheep. Anim Prod Sci 56:655-668. https://doi. org/10.1071/AN14517

Möller K, Müller T (2012) Effects of anaerobic digestion on digestate nutrient availability and crop growth: a review. Eng Life Sci 12:242-257. https://doi.org/10.1002/elsc.201100085

Nelson DW, Sommers LE (1982) Total carbon, organic carbon and organic matter. In: Page AL, Miller RH, Keeney DR (eds)
Methods of soil analysis part 2. ASA, Madison, pp 539-579. http s://doi.org/10.2134/agronmonogr9.2.2ed.c29

Øgaard AF, Krogstad T, Løes AK (2001) Potassium uptake by grass from a clay and a silt soil in relation to soil tests. Acta Agric Scand B-SP 51:97-105. https://doi.org/10.1080/09064710127617

Rehl T, Müller J (2013) CO2 abatement costs of greenhouse gas (GHG) mitigation by different biogas conversion pathways. J Environ Manag 114:13-25. https://doi.org/10.1016/j.jenvman.2012.10.049

Riva C, Orzi V, Carozzi M, Acutis M, Boccasile G, Lonati S, Tambone F, D'Imporzano G, Adani F (2016) Short-term experiments in using digestate products as substitutes for mineral $(\mathrm{N})$ fertilizer: agronomic performance, odours, and ammonia emission impacts. Sci Total Environ 547:206-214. https://doi.org/10.1016/j.scitoten v.2015.12.156

Sharpley AN, McDowell RW, Kleinman PJA (2001) Phosphorus loss from land to water: integrating agriculture and environmental management. Plant Soil 237:287-307. https://doi.org/10.1023 /A:1013335814593

Svensson K, Odlare M, Pell M (2004) The fertilizing effects of compost and biogas residues from source separated household waste. J Agric Sci 142:461-467. https://doi.org/10.1017/S00218596040 04514

Svoboda N, Taube F, Wienforth B, Kluss C, Kage H, Herrmann A (2013) Nitrogen leaching losses after biogas residue application to maize. Soil Till Res 130:60-80. https://doi.org/10.1016/j.stil 1.2013.02.006

Tambone F, Scaglia B, D’Imporzano G, Schievano A, Orzi V, Salati S, Adani F (2010) Assessing amendment and fertilizing properties of digestates through a comparative study with digested sludge and compost. Chemosphere 81:577-583. https://doi.org/10.1016 /j.chemosphere.2010.08.034

Uusitalo V, Havukainen J, Manninen K, Höhn J, Lehtonen E, Rasi S, Soukka R, Horttanainen M (2014) Carbon footprint of selected biomass to biogas production chains and GHG reduction potential in transportation use. Renew Energy 66:90-98. https://doi. org/10.1016/j.renene.2013.12.004

Vaneeckhaute C, Meers E, Michels E, Ghekiere G, Accore F, Tack FMG (2013) Closing the nutrient cycle by using bio-digestion waste derivatives as synthetic fertilizer substitutes: a field experiment. Biomass Bioenerg 55:175-189. https://doi.org/10.1016 /j.biombioe.2013.01.032

Webb J, Sörensen P, Velthof G, Amon B, Pinto M, Rodhe L, Salomon E, Hutchings N, Burczyk P, Reid J (2013) An assessment of the variation of manure nitrogen efficiency throughout Europe and an appraisal of means to increase manure- $\mathrm{N}$ efficiency. Adv Agron 119:371-442. https://doi.org/10.1016/B978-0-12-407247-3.0000 $7-\mathrm{X}$

Yu W-T, Jiang Z, Zhou H, Qiang M (2009) Effects of nutrient cycling on grain yields and potassium balance. Nutr Cycl Agroecosys 84:203-213. https://doi.org/10.1007/s10705-008-9237-4

Zhang H-M, Yang X-Y, He X-H, Xu M-G, Huang S-M, Liu H, Wang B-R (2011) Effect of long-term potassium fertilization on crop yield and potassium efficiency and balance under wheat-maize rotation in China. Pedosphere 21:154-163. https://doi.org/10.1016 /S1002-0160(11)60113-6

Zirkler D, Peters A, Kaupenjohann M (2014) Elemental composition of biogas residues: variability and alteration during anaerobic digestion. Biomass Bioenerg 67:89-98. https://doi.org/10.1016/j.biom bioe.2014.04.021

Publisher's Note Springer Nature remains neutral with regard to urisdictional claims in published maps and institutional affiliations. 